\title{
RECOVERY FROM HYPOXIC PULMONARY HYPERTENSION IN RATS
}

\author{
Hana Maxová ${ }^{1,3}$, Alena Bañasová1,3, Viera Povýšilová ${ }^{3}$, Jan Herget ${ }^{2,3}$, Martin Vizek ${ }^{1,3}$
}

Charles University in Prague, $2^{\text {nd }}$ Faculty of Medicine, Czech Republic: Department of Pathological Physiology ${ }^{1}$, Department of Physiology²; Cardiovascular Research Centre, Prague, Czech Republic ${ }^{3}$

\begin{abstract}
Summary: To characterize the time frame of changes in pulmonary arterial pressure, right ventricular hypertrophy and morphology of small pulmonary arteries male Wistar rats were exposed to isobaric hypoxia ( 3 weeks, $\mathrm{F}_{\mathrm{I}} \mathrm{O}_{2} 0.1$ ) and then let to recover on air for 1 or 5 weeks. Normoxic animals (group N) served as controls. Mean pulmonary arterial pressure (PAP), ratio of the weight of the right heart ventricle to the sum of the weights of the left ventricle and septum (RV/LV+S) and percentage of double laminated pulmonary vessels ( \% DL) were measured at the end of hypoxic exposure (group H), after 1 or 5 weeks of recovery (groups $1 \mathrm{R}$ and 5R), and in controls kept in air (group N). Three weeks in hypoxia resulted in increase in PAP, RV/LV+S and \% DL. After 1 week of recovery $\mathrm{RV} / \mathrm{LV}+\mathrm{S}$ normalized, PAP decreased, while \% DL did not change. After 5 weeks in air PAP returned to control values and \% DL diminished significantly but did not normalize. Our results suggest that recovery depends on the degree of HPH and that knowledge of the time-frame of recovery is important for future studies in our rat model.
\end{abstract}

Key words: Hypoxic pulmonary hypertension; Recovery from chronic hypoxia; Pulmonary arterial pressure; Right ventricle hypertrophy; Pulmonary vascular remodeling; Rat

\section{Introduction}

It is well documented that pulmonary hypertension induced by exposure to chronic hypoxia $(\mathrm{HPH})$ is reversible after return to normoxia $(1,8,13,19,21)$. Morphological changes accompanying HPH - hypertrophy of the right heart and thickening of peripheral pulmonary vessels are reversible as well (19). However, time frame of regression of these changes during recovery is far from being clear. Some groups found normalization of pulmonary arterial pressure (PAP) after two weeks of recovery (16) while others reported that after 6 weeks of recovery PAP decreased but reached prehypoxic values after 20 weeks $(8,9) . \mathrm{RV} / \mathrm{LV}+\mathrm{S}$ was in the some experiments normalized after two (16) or four weeks (17), but others found $\mathrm{RV} / \mathrm{LV}+\mathrm{S}$ ratio only decreased after 2 weeks (22), 4 weeks (4) or 6 weeks (8). Tozzi et al. (22) found regression of thickening of walls of peripheral pulmonary vessels after 2 weeks of recovery, Fried and Reid (4) did not find any regression after 4 weeks, Ressl et al. (20) did not see normalization after 10 weeks. The present study was, therefore, designed to specify changes of PAP, RV/LV+S and the percentage of double laminated peripheral pulmonary vessels at two stages of recovery from chronic hypoxia in our model of HPH (isobaric hypoxia, 3 weeks, $\mathrm{F}_{\mathrm{I}} \mathrm{O}_{2}$ 0.1) - early (after 1 week) and later stage (after 5 weeks) of recovery in air.

\section{Material and Methods}

Thirty two adult male Wistar rats (mean body weight $228 \pm 2$; g \pm SEM; Anlab, Prague, Czech Republic) divided into four groups were used. Experiments were performed in accordance with the European Community and NIH guidelines for using experimental animals. All procedures were approved by our institution's Animal Studies Committee.

Three groups of rats were placed in an isobaric hypoxic chamber $\left(\mathrm{F}_{\mathrm{I}} \mathrm{O}_{2} 0.1\right)(5)$ for three weeks. One group $(\mathrm{H}$, $\mathrm{n}=8$ ) was measured immediately at the end of hypoxic exposure. Remaining two groups were measured after 1 or 5 weeks of recovery in air (groups $1 \mathrm{R}, \mathrm{n}=8$ and $5 \mathrm{R}, \mathrm{n}=8$ ). Normoxic control group (group $\mathrm{N}, \mathrm{n}=8$ ) was kept in air.

Mean pulmonary arterial blood pressure (PAP, $\mathrm{mmHg}$ ) was recorded in rats anesthetized with Thiopental (ICN Czech Republic, Roztoky, Czech Republic; 40 mg/kg/ b.w. i.p.) and spontaneously breathing room air, by a catheter inserted in the pulmonary artery via the right jugular vein (7). After the PAP measurement, the heart and lungs were removed from the chest. The left ventricle plus septum (LV + $\mathrm{S}$ ) and the right ventricle (RV) were separated and weighted. Lungs were filled with formol solution and then the lung sections were stained with the hematoxylin resorcinfuchsin. Percentage of hypertensive double-laminated prealveolar vessels was counted as described previously (6). 


\section{Statistics}

Statistical analyses were performed using ANOVA with Scheffe post-hoc test. Values of $p<0.05$ were considered significant. The results are presented as means \pm SE.

\section{Results}

Rats exposed to 3 weeks of hypoxia had significantly lower body weight than normoxic controls $(\mathrm{N}=357 \pm 2$, $\mathrm{H}=256 \pm 5 \mathrm{~g}$ ).

Ratio of right ventricular weight to the sum of weights of left heart ventricle and septum $(\mathrm{RV} / \mathrm{LV}+\mathrm{S})$ was significantly higher in hypoxic group than in other groups and it was normalized after one week of recovery in air $(\mathrm{H}=0.41$ $\pm 0.02, \mathrm{~N}=0.31 \pm 0.01,1 \mathrm{R}=0.33 \pm 0.01,5 \mathrm{R}=0.31 \pm 0.01$; $\mathrm{p}<0.0001)$.

Fig. 1 shows the changes in pulmonary arterial pressure (PAP) in all groups. Hypoxia increased PAP as we expected. First week of recovery resulted in the decrease in PAP but it remained still higher than in controls. The significant difference between control and hypoxia exposed rats disappeared after five weeks of recovery.

Percentage of double laminated vessels (\% DL) did not change during the first week of recovery and decreased but did not normalize after five weeks of recovery (Fig. 2).

\section{Discussion}

The present study analyses the time course of regression of three important changes of pulmonary circulation induced by chronic hypoxia in our rat model of HPH. We found that the weight of the right ventricle returned to the physiological range during the first week of recovery. The pulmonary arterial blood pressure (PAP) recovered during five weeks in normoxia while increased percentage of double laminated peripheral pulmonary vessels persisted even after the end of the five weeks recovery. The similar time se-

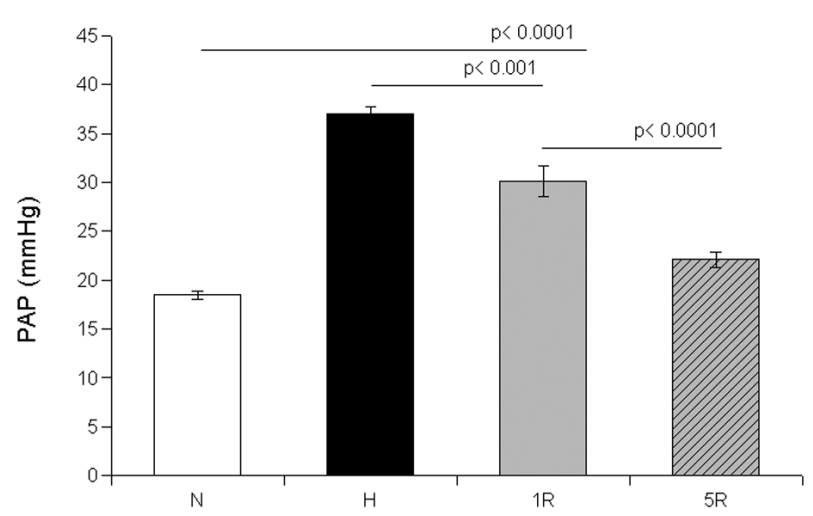

Fig. 1: Mean pulmonary arterial pressure (PAP) in rats exposed to normoxia $(\mathrm{N})$, hypoxia $(\mathrm{H})$ and recovery in air for one $(1 \mathrm{R})$ or five $(5 \mathrm{R})$ weeks. quence was reported previously $(8,9,21)$ but after a longer period than in this work.

The fact that heart weight normalization precedes the PAP normalization, reported also by others $(4,8,9,19)$, suggests that right ventricular hypertrophy is not caused by pressure load only. Our previous measurements of cardiac output in normoxic rats, rats exposed to three weeks of hypoxia and rats after 5 and 14 days of recovery in air, did not show any differences (11). If some volume overload occurs at the beginning of hypoxia it lasts for only first few days of acclimatization (14). The increased afterload could be combined with direct effect of hypoxia on the heart (14). As Pelouch et al. described (18), hypoxia increased the concentration of the collagenous proteins in the ventricular wall. This state persisted even after removal of animals from the hypoxic atmosphere when the weight of the ventricles returned to the control values. Interestingly, Bonnet et al. (3) reported that $\mathrm{RV} / \mathrm{LV}+\mathrm{S}$ ratio normalized after hypobaric hypoxia in 3 weeks but $70 \%$ of the rats showed abnormally low thickness of the right ventricular wall suggesting irreversible right ventricular dysfunction with dysplasia. The degree of tissue damage probably depends on duration of hypoxia because of absence of $\mathrm{RV} / \mathrm{LV}+\mathrm{S}$ ratio restoration after 2 weeks of recovery from 10 days of hypoxia as described Tozzi et al. (22).

Our previous experiments showed that the first week of hypoxic exposure is crucial for the development of HPH (2, $6,10)$. It seems that the discrepancies in the course of recovery are mainly due to differences in the duration and type of hypoxia (continual or intermittent, normobaric or hypobaric) resulting in the various degree of tissue radical injury and different PAP values at the end of exposure.

Nevertheless, the decrease in PAP with persisting increased wall thickness of peripheral pulmonary vessels implies importance of vasoconstriction in maintaining elevated pulmonary arterial pressure during HPH. Interestingly enough administration of Rho kinase inhibitor nearly normalized the high pulmonary arterial blood pressure and

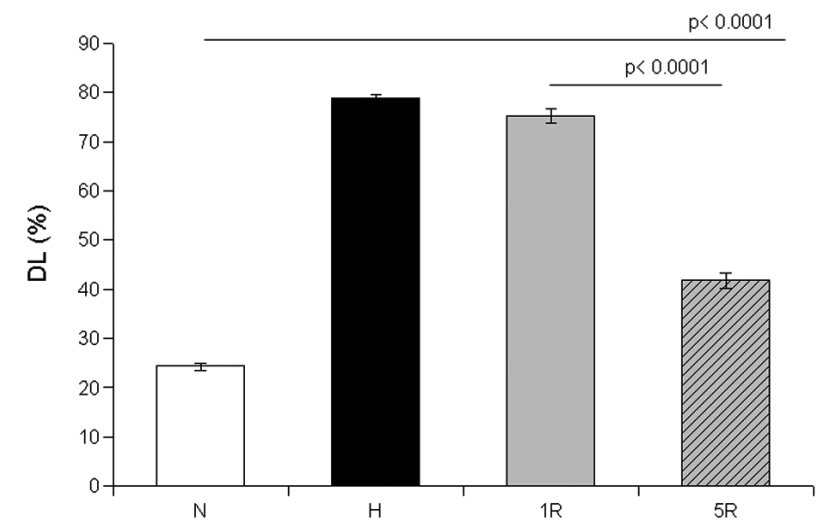

Fig. 2: Percentage of double-laminated peripheral pulmonary vessels (DL) in rats exposed to normoxia $(\mathrm{N})$, hypoxia $(\mathrm{H})$ and recovery in air for one $(1 \mathrm{R})$ or five $(5 \mathrm{R})$ weeks. 
total pulmonary resistance in chronically hypoxic rats (15). Structural remodeling of prealveolar pulmonary arteries (muscularization of media) may not be important for the increase of pulmonary vascular resistance in HPH (12).

\section{Conclusions}

While the development of HPH is intensively studied, relatively less is known about the mechanisms involved in the recovery of hypoxia-induced changes. Our results showed that during recovery from isobaric hypoxia the restoration of normal weight of the right ventricle precedes restoration of PAP while restoration of normal thickness of small pulmonary vessels walls lasts more than five weeks. The results also suggest that recovery depends on the degree of HPH. Knowledge of the time-frame of changes is important for future studies of the mechanisms of recovery from chronic hypoxia in our rat model.

\section{Acknowledgements}

This study was supported by the Grant Agency of the CR (grant No. 305/08/0108) and by the Centre for Cardiovascular Research (project No. 1M0510).

\section{References}

1. Abraham AS, Kay JM, Cole RB, Pincock AC. Haemodynamic and pathologica study of the effect of chronic hypoxia and subsequent recovery of the heart and pulmonary vasculature of the rat. Cardiovasc Res. 1971 Jan;5(1):95-102.

2. Banasova A, Maxova H, Hampl V, et al. Prevention of mast cell degranulation by disodium cromoglycate attenuates the development of hypoxic pulmonary hypertension in rats exposed to chronic hypoxia. Respiration. 2008;76(1):102-7.

3. Bonnet $\mathrm{P}$, Bonnet $\mathrm{S}$, Boissiere $\mathrm{J}$, et al. Chronic hypoxia induces nonreversible right ventricle dysfunction and dysplasia in rats. Am J Physiol Heart Circ Physiol. 2004 Sep;287(3):H1023-8.

4. Fried R, Reid LM. Early recovery from hypoxic pulmonary hypertension: a structural and functional study. J Appl Physiol. 1984 Oct;57(4):1247-53.

5. Hampl V, Herget J. Perinatal hypoxia increases hypoxic pulmonary vasoconstriction in adult rats recovering from chronic exposure to hypoxia. Am Rev Respir Dis. 1990 Sep;142(3):619-24.
6. Herget J, Novotná J, Bíbová J, Povýšilová V, Vaňková M, Hampl V. Metalloproteinase inhibition by Batimastat attenuates pulmonary hypertension in chronically hypoxic rats. Am J Physiol Lung Cell Mol Physiol. 2003 Jul;285(1):L199-208.

7. Herget J, Paleček F. Pulmonary arterial blood pressure in closed chest rats. Changes after catecholamines, histamine and serotonin. Arch Int Pharmacodyn Ther. 1972;198:107-17.

8. Herget J, Suggett AJ, Leach E, Barer GR. Resolution of pulmonary hypertension and other features induced by chronic hypoxia in rats during complete and intermittent normoxia. Thorax. 1978 Aug;33(4):468-73.

9. Kay JM, Suyama KL, Keane PM. Effect of intermittent normoxia on muscularization of pulmonary arterioles induced by chronic hypoxia in rats. Am Rev Respir Dis. 1981 Apr;123(4 Pt 1):454-8.

10. Lachmanova V, Hnilickova O, Povysilova V, Hampl V, Herget J. N-acetylcysteine inhibits hypoxic pulmonary hypertension most effectively in the initial phase of chronic hypoxia. Life Sci. 2005 May 27;77(2):175-82.

11. Maxova H, Vasilkova M, Novotna J, et al. Prevention of mast cell degranulation by disodium cromoglycate delayed the regression of hypoxic pulmonary hypertension in rats. Respiration. 2010;80(4):335-9.

12. McLoughlin P, McMurtry I. Last Word on Point:Counterpoint „Chronic hypoxiainduced pulmonary hypertension does/does not lead to loss of pulmonary vasculature“. J Appl Physiol. 2007 Oct;103(4):1456.

13. McMurtry IF, Reeves JT, Will DH, Grover RF. Reduction of bovine pulmonary hypertension by normoxia, verapamil and hexoprenaline. Experientia. 1977 Sep 15;33(9):1192-4.

14. Naeije R. Physiological adaptation of the cardiovascular system to high altitude. Prog Cardiovasc Dis. 2010 May-Jun;52(6):456-66.

15. Nagaoka T, Morio Y, Casanova N, et al. Rho/Rho kinase signaling mediates in creased basal pulmonary vascular tone in chronically hypoxic rats. Am J Physiol Lung Cell Mol Physiol. 2004 Oct;287(4):L665-72.

16. Novotna J, Bibova J, Hampl V, Deyl Z, Herget J. Hyperoxia and recovery from hypoxia alter collagen in peripheral pulmonary arteries similarly. Physiol Res. 2001;50(2):153-63.

17. Ostadal B, Prochazka J, Pelouch V, Urbanova D, Widimsky J, Stanek V. Pulmonary Vascular Changes and their reversibility Induced by Intermittent High Altitude Exposure. Prog Resp Res. 1985;20:17-25

18. Pelouch V, Kolar F, Ost'adal B, Milerova M, Cihak R, Widimsky J. Regression of chronic hypoxia-induced pulmonary hypertension, right ventricular hypertrophy, and fibrosis: effect of enalapril. Cardiovasc Drugs Ther. 1997 Apr;11(2):177-85.

19. Rabinovitch M, Gamble WJ, Miettinen OS, Reid L. Age and sex influence on pulmonary hypertension of chronic hypoxia and on recovery. Am J Physiol. 1981 Jan;240(1):H62-72.

20. Ressl J, Urbanova D, Widimsky J, Ostadal B, Pelouch V, Prochazka J. Možnost reverzibility chronické plicní hypertenze. Experimentální studie u krys. Čas Lék čes. 1975;14(114):435-8

21. Ressl J, Urbanova D, Widimsky J, Ostadal B, Pelouch V, Prochazka J. Reversibility of pulmonary hypertension and right ventricular hypertrophy induced by intermittent high altitude hypoxia in rats. Respiration. 1974 Jan;31(1):38-46.

22. Tozzi CA, Thakker-Varia S, Yu SY, et al. Mast cell collagenase correlates with regression of pulmonary vascular remodeling in the rat. Am J Respir Cell Mol Biol 1998;18(4):497-510.

Received: 26/10/2010.

Accepted in revised form: 15/02/2011.

\section{Corresponding author:}

Hana Maxová, M.D., Department of Pathological Physiology, Charles University Second Medical School, Plzeňská 130/221, 15000 Praha 5, Czech Republic; e-mail: hana.maxova@lfmotol.cuni.cz 